\title{
Invited commentary on NICE v. SIGN on psychosis and schizophrenia ${ }^{\dagger}$
}

Mark Taylor and Udayanga Perera

\author{
Summary \\ How contemporaneous guidelines interpret similar data \\ is interesting but not relevant here. Conflicts of interest \\ are important and various. Two clinically important \\ recommendations in the National Institute for Health \\ and Care Excellence (NICE) guideline CG178 deserve \\ re-visiting.
}

\section{Declaration of interest}

M.T. was co-chair of SIGN 131, and has received hospitality or fees from Lundbeck, Janssen, Roche, and Otsuka in the past 3 years

\section{Copyright and usage}

(c) The Royal College of Psychiatrists 2016.
How contemporaneous guidelines interpret similar data is interesting but not relevant here. Switching the discussion from an analysis of the National Institute for Health and Care Excellence (NICE) guideline CG178 ${ }^{1}$ to a comparison of CG178 with the Scottish Intercollegiate Guidelines Network guidance $131^{2}$ (SIGN 131) is simply an obfuscatory diversion. Our original editorial $^{3}$ only mentions SIGN 131 twice - once in conjunction with the British Association for Psychopharmacology schizophrenia guideline - and we did not 'claim', as Kendall et al ${ }^{4}$ wrongly state, that SIGN 131 'was unbiased'. Furthermore, SIGN 131 was not an 'update' or 'largely based' on the 2009 NICE guideline CG82, ${ }^{5}$ as also stated twice, beyond noting that NICE did kindly furnish SIGN 131 with their meta-data to 2007, on which CG82 was derived. The SIGN 131 multidisciplinary group then conducted their own systematic reviews and interpretation programme of any subsequent relevant literature. SIGN commenced in 1993 and lent its methodology to NICE when they began in 1999, so it is unclear which is 'more rigorous'.

\section{Conflicts of interest and bias}

Impugning the opposition is another classic debating trick. Kendall et al suggest that we have 'succumbed to bias' without further explanation. Examining the basis or validity for the recommendations in CG178 does not mean the questioner is biased. To question is to be scientific, and our editorial merely states that CG178 is 'open to a critique of bias'. Conflicts of interest are important in any discussion of bias, and can be varied. ${ }^{6,7}$ Potential conflicts of interest here might include: training fees, grant applications and publication royalties for the recommended interventions; researcher or guideline allegiance; receiving money from NICE to promote NICE; and putting forward research questions that mirror the authors' own career interests. NICE itself $^{7}$ and others ${ }^{8}$ have expressed concern regarding the governance of NICE guideline groups.

\section{Recommendations re-visited}

Two clinically important CG178 recommendations deserve re-visiting. First, authorities ${ }^{9}$ regard at-risk mental states (ARMS) - for which CG178 has a whole new chapter - as an unreliable category with little predictive validity. Kendall et al state that CG178 recommended to 'offer CBT for people with ARMS' based

'See pp. 316-319, this issue. on a meta-analysis they themselves conducted, without commenting on the ARMS construct validity, fidelity of the intervention or resource implications.

Second, advocating cognitive behavioural therapy for psychosis (CBTp) as sole therapy (i.e. no medication of any sort) during the first month of first-episode psychosis arguably lacks clinical face validity and could potentially be dangerous given the high suicide rate in this population. ${ }^{10}$ Extrapolating recommendations from 'sparse' data is also ill-advised. Moreover, the practical issues of what happens when CBTp is refused or not available locally are simply not addressed by CG178.

In a serious disorder such as schizophrenia, all effective treatments are welcome. CBTp may well have a small benefit (effect size 0.2) in psychosis, ${ }^{11}$ although recently there have been concerns regarding the reproducibility of psychology studies. ${ }^{12}$

Our original editorial used tendentious language with the aim of provoking rational debate - a pillar of scientific progress. It seems we have partially succeeded in that aim.

Mark Taylor, MD, FRCPsych, FRANZCP, Intensive Home Treatment Team, Royal Edinburgh Hospital, Edinburgh, UK, and University of Queensland, Brisbane, Australia; Udayanga Perera, MD, Department of Psychiatry, District General Hospital, Monaragala, Sri Lanka.

Correspondence: Mark Taylor, Royal Edinburgh Hospital, Edinburgh EH10 5HF UK. Email: marktaylor2@nhs.net

First received 25 Nov 2015, final revision 17 Dec 2015, accepted 21 Dec 2015

\section{References}

1 National Collaborating Centre for Mental Health. Psychosis and Schizophrenia in Adults: The NICE Guideline on Treatment and Management (Updated Edition) (Clinical Guideline CG178). National Institute for Health and Care Excellence, 2014.

2 Scottish Intercollegiate Guidelines Network. Management of Schizophrenia (SIGN 131). SIGN, 2013.

3 Taylor M, Perera U. NICE CG178 Psychosis and Schizophrenia in Adults: Treatment and Management - an evidence-based guideline? Br J Psychiatry 2015; 206: 357-9.

4 Kendall $\mathrm{T}$, Whittington $\mathrm{CJ}$, Kuipers $\mathrm{E}$, Johnson S, Birchwood MJ, Marshall M, et al. NICE $v$. SIGN on psychosis and schizophrenia: same roots, similar guidelines, different interpretations. Br J Psychiatry 2016; 208: 316-9.

5 National Institute for Clinical Excellence. Schizophrenia: Core Interventions in the Treatment and Management of Schizophrenia in Primary and Secondary Care (Clinical Guideline CG82). NICE, 2009.

6 Maj M. Non-financial conflicts of interests in psychiatric research and practice. Br J Psychiatry 2008; 193: 91-2. 
7 Dragioti E, Dimoliatis I, Evangelou E. Disclosure of researcher allegiance in meta-analysis and randomised controlled trials of psychotherapy: a systematic appraisal. BMJ Open 2015; 5: e007206.

8 NICE Triennial Review Team. Report of the Triennial Review of the National Institute for Health and Care Excellence: 63-5. Department of Health, 2015.

9 Coghill D. Are NICE guidelines losing their impartiality (letter)? Br J Psychiatry 2015; 207: 271.
10 Van Os J, Murray RM. Can we identify and treat 'schizophrenia light' to prevent true psychotic illness? BMJ 2013; 346: f304.

11 Hor K, Taylor M. Suicide and schizophrenia: a systematic review of rates and risk factors. J Psychopharmacol 2010; 24 (4 suppl): 81-90.

12 Turner DT, van der Gaag M, Karyotaki E, Cuijpers P. Psychological interventions for psychosis: a meta-analysis of comparative outcome studies. Am J Psychiatry 2014; 171: 523-38.

13 Open Science Collaboration. Estimating the reproducibility of psychological science. Science 2015; 349: 6251.

\section{psychiatry in history}

\section{An 18th-century view of demonomania. 2: Vampirism - stories}

\author{
Fiona Subotsky
}

The three stories are taken from Martinus Martini's 1782 dissertation on demonomania.

The Man from Morea

A man fled from Morea because he had committed a serious crime and took himself to Milo island - by which he escaped judicial penalty but not ecclesiastical condemnation. As he had been rightly ejected from the communion of believers, he was buried in a remote deserted place when he died. The inhabitants of the island were tormented at night by spectres, and so, stricken with fear, they decided to exhume the body of the dead man. When they did this the man who had died not long before was now apparently living; the veins were swollen with blood and the tomb was filled with grapes, apples, nuts and other things to eat.

The islanders referred the issue to the Patriarch of Constantinople, asking that he be reconciled to the Church and be absolved by dire execrations. Meanwhile they brought the corpse to the temple and there committed it to earth. Suddenly during prayers and other sacred acts a murmuring noise was heard in the tomb. The people believed this had occurred at the very same time as the Patriarch had given absolution.

Martini remarks that 'Great faith is required'!

The story of Plogowitz

In 1725 .. . Plogovitz strangled nine people over the course of eight days after his funeral ... He was dug up, and there was no corruption, no putrefaction, no blemish whatever except for his nose ... His hair, beard, nails had grown ... His mouth was full of blood, which people claimed he had drained from the veins of living men. They transfixed his heart with a sharp stake, which caused much fresh blood to pour out of the mouth and ears. Then his corpse was condemned to the flames.

The Story of Arnold Paole

A soldier called Arnold Paole had died after a fall ... While still alive he had said that having been previously tormented by a vampire, he had eaten earth from its tomb, and had washed himself with the blood in order to overcome this evil ... Twenty or thirty days after his death many people complained about Paole, because they were tormented by him, indeed by now he had killed four people... Around forty days after the death his corpse was exhumed and found to be uncorrupted; fresh blood flowed from the eyes, ears and mouth, and new nails were growing ... When they transfixed the heart with a stake, it gave out a perceptible sound, and the corpse was consigned to the flames.

The introduction to this short series on vampirism was published in the March issue of the BJPsych. 